\title{
Gender differences in white matter pathology and mitochondrial dysfunction in Alzheimer's disease with cerebrovascular disease
}

\author{
Xavier Gallart-Palau', Benjamin S. T. Lee', Sunil S. Adav', Jingru Qian', Aida Serra', Jung Eun Park,
} Mitchell K. P. Lai ${ }^{2}$, Christopher P. Chen ${ }^{2,3}$, Raj N. Kalaria ${ }^{4}$ and Siu Kwan Sze ${ }^{1 *}$

\begin{abstract}
Background: Dementia risk in women is higher than in men, but the molecular neuropathology of this gender difference remains poorly defined. In this study, we used unbiased, discovery-driven quantitative proteomics to assess the molecular basis of gender influences on risk of Alzheimer's disease with cerebrovascular disease (AD + CVD).

Results: We detected modulation of several redox proteins in the temporal lobe of AD + CVD subjects, and we observed sex-specific alterations in the white matter (WM) and mitochondria proteomes of female patients. Functional proteomic analysis of $A D+C V D$ brain tissues revealed increased citrullination of arginine and deamidation of glutamine residues of myelin basic protein (MBP) in female which impaired degradation of degenerated MBP and resulted in accumulation of non-functional MBP in WM. Female patients also displayed down-regulation of ATP subunits and cytochromes, suggesting increased severity of mitochondria impairment in women.

Conclusions: Our study demonstrates that gender-linked modulation of white matter and mitochondria proteomes influences neuropathology of the temporal lobe in $A D+C V D$.
\end{abstract}

Keywords: Alzheimer's disease, Cerebrovascular disease, Dementia, Temporal lobe, White matter, Citrullination, Deamidation, Proteomics, iTRAQ

\section{Background}

Dementia prevalence and severity in women are significantly higher than in men after controlling for expected lifespans $[1,2]$, but the neuropathological basis of this gender bias is currently unknown. Alzheimer's disease is the most common form of dementia in the elderly, the majority of whom also undergo variable cerebrovascular disease (AD + CVD) [3]. Affected individuals display a complex brain pathology characterized by senile plaques with microinfarcts, as well as a poorly understood degeneration of the small vessels that supply blood to the brain [4-7]. While vascular involvement appears to be closely linked with the

\footnotetext{
* Correspondence: sksze@ntu.edu.sg

'Division of Chemical Biology \& BioTechnology, School of Biological Sciences, Nanyang Technological University, 60 Nanyang Drive, Singapore 637551, Singapore

Full list of author information is available at the end of the article
}

extent of white matter (WM) pathology [8-10], it remains poorly defined how small vessel disease influences the clinical course of $\mathrm{AD}+\mathrm{CVD}$.

Restriction of blood flow to the brain results in WM tissue damage, leading to neurodegeneration and eventual dementia [11-15]. WM pathology contributes to cognitive impairment and long-term disability in elderly subjects via multiple mechanisms that do not depend on amyloid formation [16, 17]. Indeed, brain WM exhibits a complex composition of different molecules that can be modified to influence brain function, including both lipid molecules and proteins such as $2^{\prime}, 3{ }^{\prime}$-cyclic nucleotide $3^{\prime}$-phosphodiesterase (CNP), myelin proteolipid protein (PLP), and myelin basic protein (MBP) [18]. CNP and PLP, are involved on the maturation of oligodendrocytes $[19,20]$, while MBP regulates myelination and initiates essential signaling pathways in brain cells 
[21]. Brain MBP is known to be susceptible to degenerative protein modifications (DPMs) including deamidation and citrullination $[22,23]$, and myelin degeneration can directly impair cognitive function due to disruption of neuronal circuits [24, 25], but the molecular profile of brain myelin proteins in $\mathrm{AD}+\mathrm{CVD}$ has yet to be deciphered.

Degeneration of myelin sheaths causes axon disintegration, leading to impaired mitochondrial function and decreased provision of the essential molecules needed to maintain WM integrity [26-28]. Previous studies have also identified that changes in the molecular composition of MBP influence white matter pathology in vascular dementia (VaD) $[15,22,29]$, and that excess DPMs promote proteinopathy and neurodegeneration in both $\mathrm{AD}$ and $\mathrm{VaD}$ [30]. However, it remains unclear to what extent white matter pathology depends on DPMinduced proteinopathy in AD-related human dementias. Intriguingly, a previous study reported gender-specific differences on the accumulation of deamidation in rodent brain proteins [31]. Similarly, prevalence and severity of citrullination-associated diseases in the central nervous system is significantly higher in women than in men [32] what suggests that these two DPMs could also underpin the increased dementia risk observed in human females. We therefore used discovery-driven quantitative proteomics [33] to investigate the molecular basis of gender influences on the pathology of $\mathrm{AD}+\mathrm{CVD}$.

\section{Results}

\section{White matter pathology is influenced by gender in $A D+$ CVD}

In order to assess the molecular basis of gender influences on risk of Alzheimer's disease with cerebrovascular disease (AD + CVD), we first assessed the extent of myelin rarefaction/density loss in post-mortem brain tissues from male and female patients.

While there were no gender-specific differences noted during post-mortem evaluation of brain myelin density in $\mathrm{AD}+$ CVD (Table 1), analysis of the temporal lobe proteome of dementia patients revealed significant up-regulation of myelin proteins CNP, PLP and hyaluronan proteoglycan 2 (HPLN2), which were further increased only in female patients (Fig. 1a, Additional file 1: Table S1). PLP enrichment in the temporal lobe of female $\mathrm{AD}+\mathrm{CVD}$ was also validated in another independent cohort by western blot (Fig. 1b and c).

Intriguingly, we observed down-regulation of the myelin-associated protein Cathepsin D in women with dementia while the rest of myelin proteins identified in that group were significantly upregulated (Fig. 1a). Furthermore, the protein neural cell adhesion molecule (NCAM1) involved on functional response to white matter injury was only up-regulated in male patients (Fig. 1a). These data indicated that unbiased quantitative profiling of the human brain proteome can detect gender-specific differences in white matter pathology from patients with $\mathrm{AD}+\mathrm{CVD}$ that were not apparent from conventional post-mortem evaluation.

The brain protein myelin associated glycoprotein (MAG) is highly susceptible to ischemia-induced degradation and its levels do not vary in the mammal's brain by the effect of gender [34]. Similarly, PLP positively correlates with severity of white matter pathology in small vessel disease [35], hence MAG/PLP ratio can be used as a proxy measure of disease severity in affected patients $[35,36]$. Using this approach in our dementia samples, we observed that MAG/PLP ratio was significantly lower in females (0.2) than in males (0.5), indicating greater severity of WM pathology in women with AD + CVD. Since both genders exhibited comparable expression levels of MAG protein, which is readily degraded under ischemic conditions [35], these data suggested that both men and women may undergo a similar extent of ischemic injury in AD + CVD, but that subsequent effects on the myelin proteome and PLP expression differ between genders.

\section{Sex-influenced modification of myelin basic protein in $A D+C V D$}

Degenerative protein modifications (DPMs) including deamidation and citrullination are thought to underpin loss of protein function in the brains of dementia patients [37-40], so we next assessed whether protein modification profiles differed between male and female $\mathrm{AD}+\mathrm{CVD}$. To do this, we performed functional proteomic analysis by studying the quantitation iTRAQ reporter area of all modified peptides for each identified peptide of the BA21 brain proteome. Using our unbiased discovery approach, we identified that myelin basic protein (MBP) exhibited the most extensive occurrence of DPMs in whole proteome of $\mathrm{AD}+\mathrm{CVD}$ subjects as mapped in Fig. 2a. Stoichiometry of deamidation at glutamine (Gln) and asparagine (Asn) residues covered $\sim 30 \%$ of all identified MBP constituent peptides (Fig. 2b). When compared with controls, AD + CVD patients exhibited increased ratio of deamidation in brain MBP, and this was more extensive in women than in men (Fig. 2c and d), particularly at residues Gln 281, 255, 236 and 215 (Fig. 2e), suggesting increased incidence of DPMs in women with dementia. Consistent with this concept, we also observed significantly higher deamidation of Asn 217 in brain MBP only in female AD + CVD patients (Fig. 2f). Further stoichiometric analysis revealed that citrullination of arginine (Arg) residues affected $12 \%$ percent of MBP constituent peptides in $\mathrm{AD}+\mathrm{CVD}$ (Fig. 2g), and we detected hyper-citrullinated MBP only 
Table 1 Demographic and clinical data of dementia subjects and age-matched control subjects. 1. Post-mortem delay

\begin{tabular}{|c|c|c|c|c|c|c|c|}
\hline \multicolumn{8}{|c|}{ Age-matched control subjects } \\
\hline Gender & Age & $\mathrm{PM}^{\mathrm{a}}$ delay & Cognitive assessment & Cog. exam. & Braak & CERAD & Neuropathology \\
\hline M & 72 & 17 & Normal control & Retrospective Interview & 1 & Sparse & Mild AD-like pathology \\
\hline M & 75 & 20 & Normal control & Retrospective Interview & 0 & None & $\begin{array}{l}\text { Scattered microinfarcts (in right hemisphere: hippocampal CA2/3, } \\
\text { putamen, caudate, external medullary lamina) and SVD: Foci of } \\
\text { arteriosclerosis mainly in white matter }\end{array}$ \\
\hline $\mathrm{F}$ & 68 & 75 & Normal control & Retrospective Interview & 1 & Sparse & $\begin{array}{l}\text { Mild cerebral amyloid angiopathy. A right frontal microinfarct and } \\
\text { small lacunar infarct in the left putamen. Infarcts in both cortex and } \\
\text { basal ganglia }\end{array}$ \\
\hline $\mathrm{F}$ & 78 & 23 & Normal control & Retrospective Interview & 2 & Sparse & Mild AD-like pathology \\
\hline $\mathrm{F}$ & 82 & 26 & Normal control & Retrospective Interview & 0 & N.A. & No detected AD or CVD pathology \\
\hline $\mathrm{F}$ & 87 & 14 & Normal control & Retrospective Interview & N.A. & N.A. & Low mean density of neocortical tangles = 2.5 per mm2. \\
\hline $\mathrm{F}$ & 99 & 19 & Normal control & Retrospective Interview & N.A. & None & No detected AD or CVD pathology \\
\hline $\mathrm{F}$ & 86 & 40 & Normal control & Retrospective Interview & 1 & N.A. & No detected AD or CVD pathology \\
\hline $\mathrm{F}$ & 75 & 31 & Normal control & Retrospective Interview & N.A. & N.A. & No detected AD or CVD pathology \\
\hline $\mathrm{F}$ & 81 & 51 & Normal control & Retrospective Interview & N.A. & N.A. & No detected AD or CVD pathology \\
\hline Mean & $80.3 \pm 8.9$ & $31.6 \pm 19$ & & & & & \\
\hline \multicolumn{8}{|c|}{$A D+C V D$ subjects } \\
\hline Gender & Age & $\mathrm{PM}^{\mathrm{a}}$ delay & Cognitive assessment & Cog. exam. & Braak & CERAD & Neuropathology \\
\hline M & 83 & 71 & 1 y. cog imp. & M.M.S.E $=18$ & 4 & Moderate & $\begin{array}{l}\text { Mixed pathology - AD and SVD (predominantly microinfarcts in } \\
\text { frontal lobe \& perivascular lacunae in basal ganglia). Cavernous } \\
\text { hemangioma in right ventrolateral posterior centrum semiovale. } \\
\text { Loss of myelin in brain capsules. }\end{array}$ \\
\hline M & 72 & 29 & 7 y. cog imp. & M.M.S.E $=20$ & 4 & Frequent & $\begin{array}{l}\text { Mixed AD and CVD. Microinfarcts in putamen. Loss of myelin in } \\
\text { internal capsule }\end{array}$ \\
\hline M & 84 & 42 & 8 y. cog imp. & M.M.S.E $=13$ & 5 & N.A. & $\begin{array}{l}\text { Mixed pathology AD with vascular dementia and severe cerebral } \\
\text { amyloid angiopathy. }\end{array}$ \\
\hline M & 82 & 38 & 1 y. dementia & M.M.S.E $=16$ & 6 & N.A. & $\begin{array}{l}\text { Mixed pathology AD with old infarcts in the temporal cortex right } \\
\text { hemisphere. CVD affecting parietal and occipital lobes. Microinfarcts } \\
\text { in caudate and putamen. Focal loss of myelin in brain capsules. }\end{array}$ \\
\hline M & 64 & 24 & 1 y. dementia & M.M.S.E $=20$ & N.A. & N.A. & $\begin{array}{l}\text { Mixed pathology AD + CVD affecting middle temporal gyrus, } \\
\text { parietal and occipital lobes. Myelin affectation in brain capsules. }\end{array}$ \\
\hline Mean & $77 \pm 8.7$ & $41 \pm 18$ & & & & & \\
\hline $\mathrm{F}$ & 93 & 18 & 2 y. dementia & S.I.B $=75 / 100$ & 5 & Frequent & $\begin{array}{l}\text { Mixed pathology AD + CVD affecting parietal and temporal lobes. } \\
\text { Myelin affectation in brain capsules. }\end{array}$ \\
\hline $\mathrm{F}$ & 89 & 72 & 4 y. cog. imp. & M.M.S.E $=16$ & 4 & N.A. & $\begin{array}{l}\text { Mixed pathology } A D+C V D \text { affecting temporal lobes and brainstem. } \\
\text { Severe myelin affectation in medial and internal temporal gyrus. }\end{array}$ \\
\hline
\end{tabular}


Table 1 Demographic and clinical data of dementia subjects and age-matched control subjects. 1. Post-mortem delay (Continued)

\begin{tabular}{|c|c|c|c|c|c|c|c|}
\hline $\mathrm{F}$ & 89 & 32 & 3 y. cog. imp. & M.T.S $=5 / 37$ & 5 & N.A. & $\begin{array}{l}\text { Mixed pathology AD + CVD. Severe changes in hippocampus. } \\
\text { Neurofibrillary tangles in raphe nucleus. }\end{array}$ \\
\hline $\mathrm{F}$ & 92 & 12 & 5 y. dementia & M.M.S.E $=20$ & 5 & N.A. & $\begin{array}{l}\text { Mixed pathology AD }+C V D \text { affecting middle temporal gyrus and } \\
\text { parietal/occipital lobes. Severe myelin affectation in temporal cortex. }\end{array}$ \\
\hline $\mathrm{F}$ & 86 & 99 & 2 y. dementia & M.M.S.E $=20$ & 6 & N.A. & Mixed pathology AD + CVD. Moderate temporoparietal infarcts. \\
\hline Mean & $89.8 \pm 2.8$ & $46.6 \pm 37.5$ & & & & & \\
\hline
\end{tabular}

apost-mortem delay 

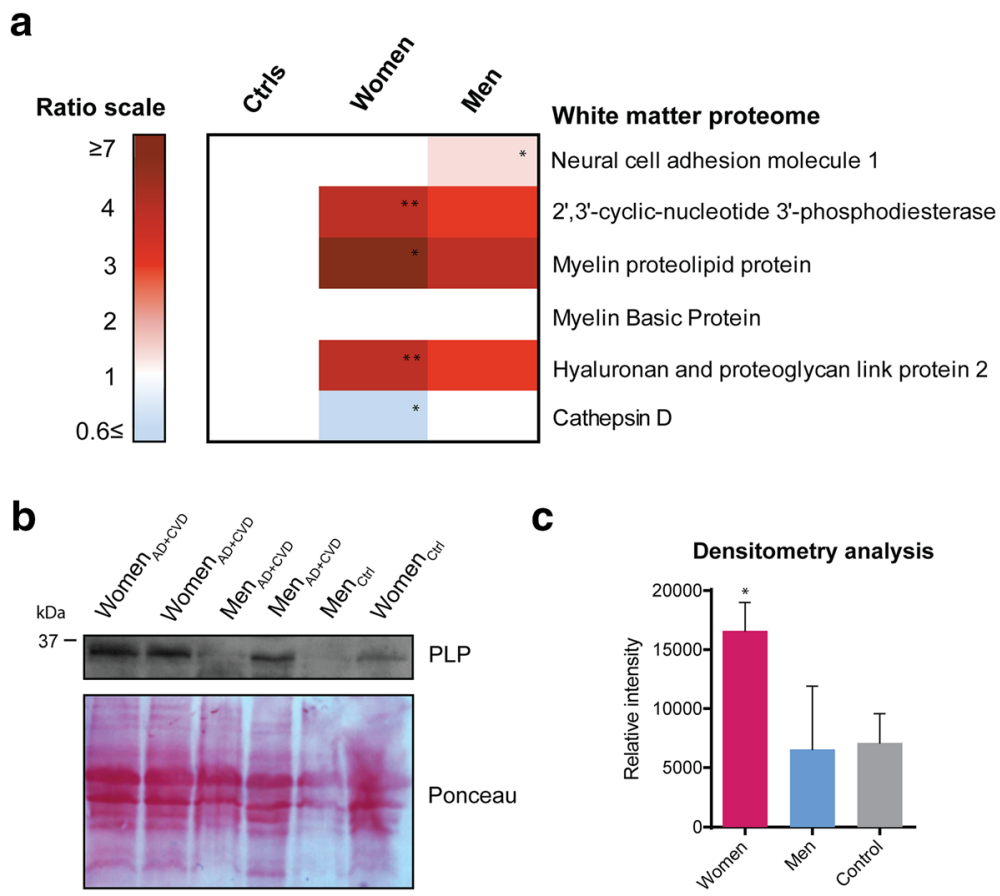

C

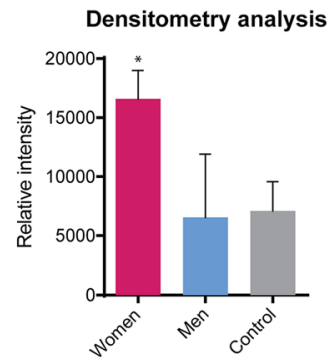

Fig. 1 a Heatmap displaying protein enrichment/depletion in the white matter proteome of male and female AD + CVD subjects compared to age-matched controls. Log ratios in AD + CVD subjects were normalized to controls (controls ratio $=1$ ). Red values represent protein enrichment, blue values represent protein depletion and white values indicate no change in the ratio scale. Protein names were listed on the right side of each heat map line. Significance level of modified proteins in each group were indicated at the upper right corner of each box $\left(^{*} p<0.05\right.$ and gender difference $\geq 0.2$; ${ }^{* *} p<0.001$ and gender difference $\geq 0.9$ ). Tabular data of values shown in this heat map can be found in Additional file 1 : Table S1. $\mathbf{b}$ Validation of the PLP enrichment in the temporal lobe of AD + CVD women was confirmed by Western blot in individual subjects from an independent cohort. c Densitometry analysis of Western blot signal normalized by Ponceau intensities. Significance level in graph of PLP signal in women relative to controls $\left({ }^{*} p<0.05\right)$

in female patients (Fig. 2h). Citrullination of Arg residue 256 was significantly increased in women with dementia (Fig. 2i), which also displayed extensive citrullination of Arg residues 159 and 231, whereas DPM of these residues did not differ between male dementia patients and controls (Fig. 2i). These data suggested that women with $A D+C V D$ exhibit significantly higher brain protein DPMs than male patients or controls.

\section{Sex-influenced degradation of myelin basic protein in AD + CVD}

Since WM pathology in $\mathrm{AD}$ and $\mathrm{VaD}$ is associated with accumulation of degenerated MBP (dMBP) [15], we next assessed whether the sex-specific DPMs detected here could influence the degradation profile of brain MBP. In $\mathrm{dMBP}$, the protein sequence QDENPVV (residues 8288 ) is susceptible to degradation by cathepsin D due to the 3D structure of $\mathrm{dMBP}$ and generates the byproduct peptide TQDENPVVHF (residues 81-90) [41-43]. We therefore assessed whether women and men with $\mathrm{AD}+$ CVD exhibited differential deamidation of Gln residue 82 in the exposed region of dMBP. Using this approach, we observed that women with dementia displayed increased stoichiometry of deamidation in Gln 82, which was associated with impaired degradation of this protein region (Fig. 3a) and accumulation of dMBP. These data suggested that dMBP due to Gln deamidation may be more resistant to proteolytic cleavage similar to other proteins reported previously [30, 44] and to removal from brain tissues of female AD + CVD patients. In contrast, $\mathrm{AD}+\mathrm{CVD}$ patients did not exhibit any change on the degradation ratio of the cathepsin D byproduct YLATASTMDHAR\#, despite that increased level of peptide citrullination was detected for this byproduct in women with dementia (Fig. 3b). These data indicated that sexspecific degradation of brain proteins in $A D+C V D$ varies across the proteome in BA21, with MBP being the most heavily modified protein in the brain of female with dementia.

Female AD + CVD is associated with specific modifications of the temporal lobe and mitochondria proteomes

Women with cognitive disorders have been reported to display impaired glutamine-glutamate metabolism in the brain $[45,46]$, and may exhibit mitochondria dysfunction associated with defective hormone signaling [47], so 
a
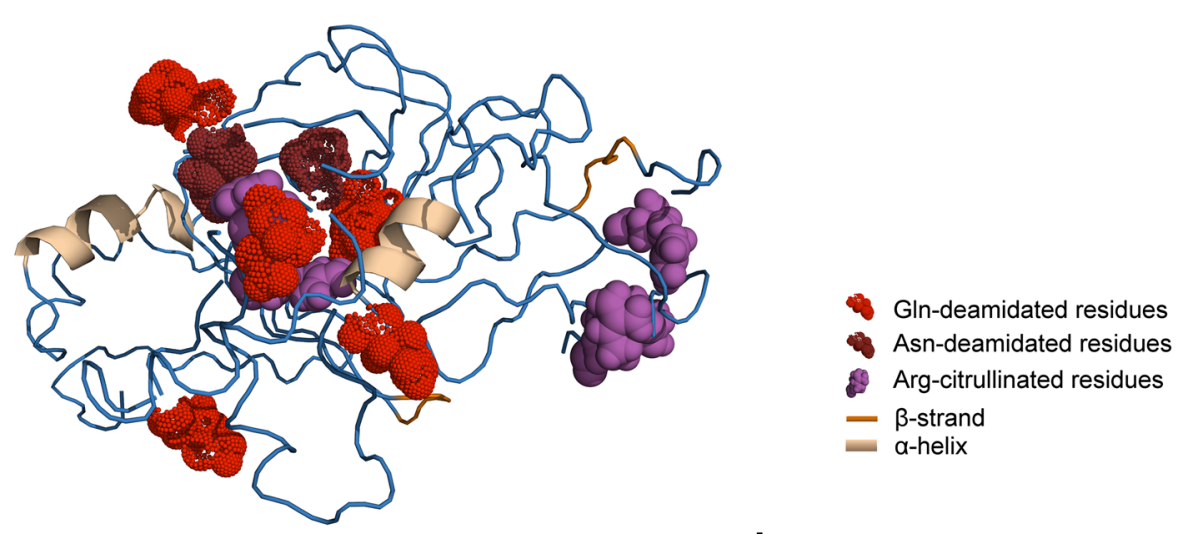

b Stoichiometry of MBP deamidation

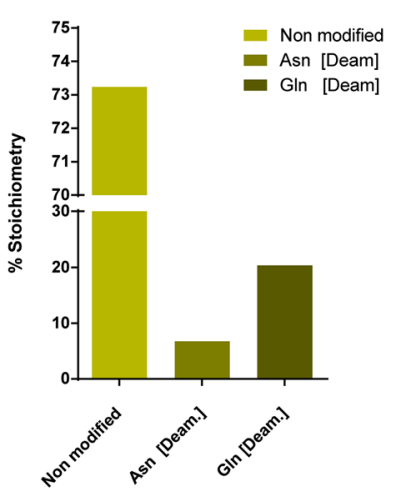

e Site distribution of GIn deamidation areas

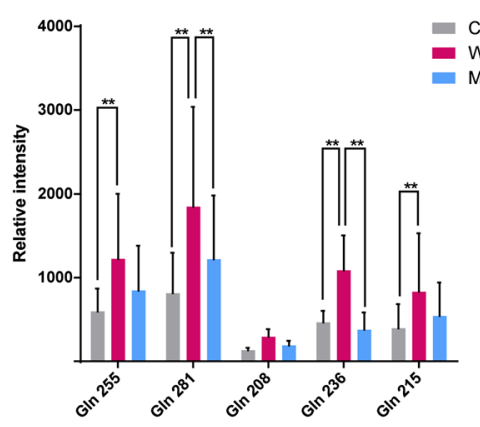

h

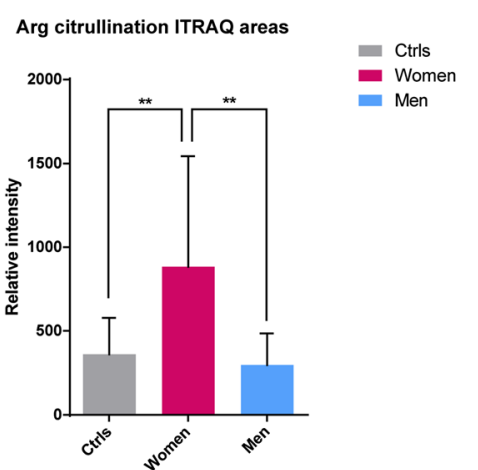

C GIn deamidation ITRAQ areas

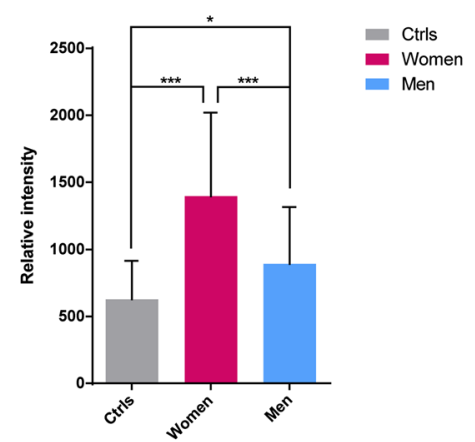

f

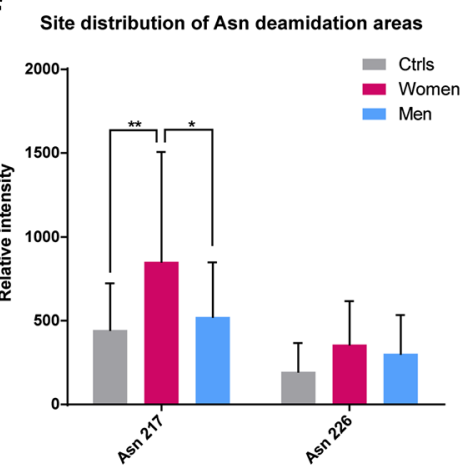

d Asn deamidation ITRAQ areas

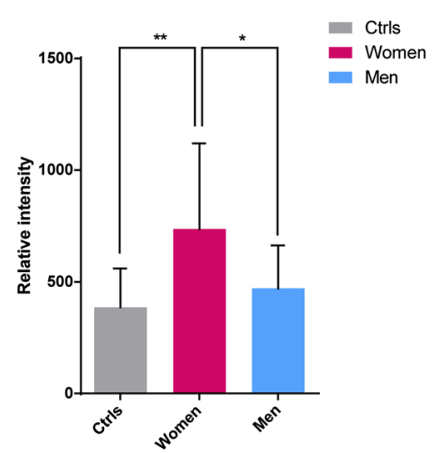

9 Stoichiometry of MBP citrullination

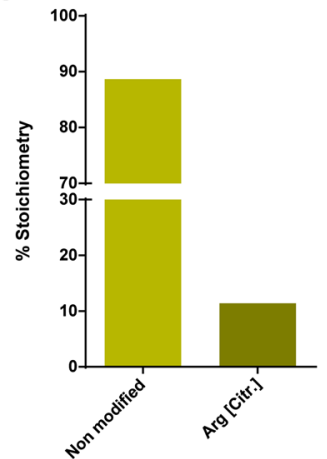

Arg [Citr]

Non modified

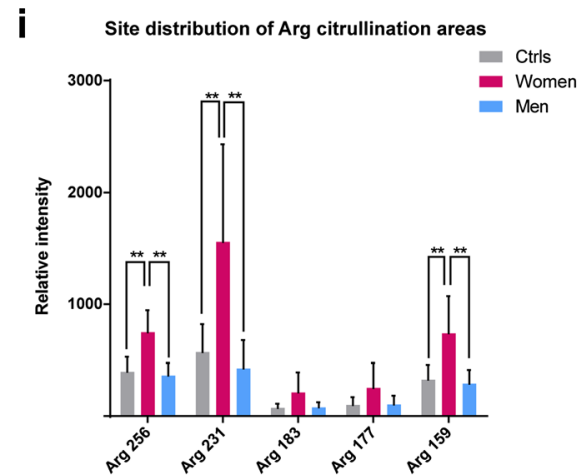

Fig. 2 (See legend on next page.) 
(See figure on previous page.)

Fig. 2 Degenerative modifications in MBP. a 3D structural modelling of MBP sequence in AD + CVD, showing modified sites including Arg citrullination and GIn/Asn deamidation. $\mathbf{b}$ Stoichiometry of MBP deamidation considering the percentage of all confidentially identified peptides in all groups ( $A D+C V D$ subjects and controls). c Relative level of Gln deamidation considering all the identified sites from the obtained iTRAQ peak intentities in age-matched controls, $A D+C V D$ women and $A D+C V D$ men. $\mathbf{d}$ Relative levels of Asn deamidation considering all the identified sites from the obtained iTRAQ peak intentisites in age-matched controls, AD + CVD women and AD + CVD men. e Site distribution of GIn deamidation peak intensities in age-matched controls, AD + CVD women and AD + CVD men. $\mathbf{f}$ Site distribution of Asn deamidation peak intensities in age-matched controls, AD + CVD women and AD + CVD men. $\mathbf{g}$ Stoichiometry of MBP citrullination considering the percentage of all confidentially identified peptides in all groups (AD +CVD subjects and controls). $\mathbf{h}$ Relative level of Arg citrullination across all sites based on the obtained ITRAQ areas in age-matched controls, women with dementia, and men with dementia. i Site distribution of Arg citrullination iTRAQ area intentities in MBP from age-matched controls, women with dementia, and men with dementia. Significance level in graphs $\left(^{*} p<0.05\right.$; ** $p<0.001)$

we next sought to identify sex-specific modulation of the temporal lobe and mitochondria proteomes in $\mathrm{AD}+$ CVD. Whole temporal lobe proteome displayed increased levels of Gln deamidation in AD + CVD subjects relative to age-matched controls $(3.90 \%$ female dementia, $3.87 \%$ male dementia, $3.52 \%$ age-matched controls; chi square 27.698 with one degree of freedom, $p$-value $<0.001)$ and in female patients we detected increased levels of the enzyme carbonyl reductase 1 (NADPH1) compared with either male patients or controls (iTRAQ ratio female/controls $2.09 \pm 0.13$; $p$-value $<0.001$; gender ratio female/male 2.36). Since NADPH1 can promote deamidation of Gln residues [48], and we detected a reduction in glutamine synthetase (GS) levels in women with dementia (iTRAQ ratio female/controls $0.5 \pm 0.09$; $p$-value 0.002; gender ratio female/male 0.45 ), these data could explain the impaired glutamine-glutamate metabolism identified in the temporal lobe of female dementia patients. Indeed, we also found numerous genderspecific deamidations of various Gln amino acid pairs and a single asparagine amino acid pair in the temporal lobe of AD + CVD subjects (Fig. 4a and b). We also observed increased citrullination of Arg residues in female $\mathrm{AD}+\mathrm{CVD}$ patients compared with male patients, but only at a limited number of amino acid pairs (Fig. 4c).

Dementia pathology is strongly associated with mitochondrial production of reactive oxidative species (ROS), and in our $\mathrm{AD}+\mathrm{CVD}$ samples we detected up-regulation of the dismutase protein superoxide dismutase- 1 as well as down-regulation of aldehyde dehydrogenase and mitochondrial creatine kinase-U-type relative to controls (Fig. 5, Additional file 2: Table S2). While evidence of mitochondria dysfunction was apparent in both men and women with dementia, female patients also exhibited dysregulation of the $\mathrm{D}$ and $\mathrm{O}$ subunits of ATP synthase, together with downregulation of cytochromes, NADH ubiquinone alpha subunits (5 and 8) and chaperone stress-70 (Fig. 5, Additional file 2: Table S2), indicating that perturbation of the mitochondria proteome in $\mathrm{AD}+\mathrm{CVD}$ is more pronounced in women than in men. Together, these data confirm a positive association between WM pathology and mitochondria dysfunction in the temporal lobe of $A D+C V D$ subjects, and suggest that dysregulation of mitochondrial ATP synthesis; redox activity and cytochrome function represent gender-specific neurodegenerative processes in $\mathrm{AD}+\mathrm{CVD}$.

\section{Discussion}

In the current study, we used discovery-driven quantitative proteomics to uncover gender influences on myelin neuropathology and dysfunctional mitochondria proteomes in the temporal lobe of patients with $\mathrm{AD}+\mathrm{CVD}$. The data from this study provide novel insight into the molecular basis of the increased dementia risk and disease severity observed in women that develop AD + CVD.

Despite that post-mortem evaluation of myelin density failed to detect gender differences on white matter pathology in patients with $A D+C V D$, the data from quantitative profiling of the brain proteome clearly revealed the gender-specific molecular pathology of the affected WM. While we detected similar levels of MAG protein in men and women with dementia, suggesting a comparable extent of ischemic injury in both genders based on MAG/ PLP ratio [35, 36], the severity of WM pathology observed in women was greater than that observed in men. Accumulation of $\mathrm{dMBP}$ in the temporal lobe is a key indicator of WM pathology in dementia $[15,49]$. In disease settings, hyper-citrullination of MBP is thought to increase protein degradation by cathepsin $\mathrm{D}$ and other enzymes, leading to axonal dysfunction and progressive loss of neuronal function $[43,50,51]$. In-line with predictions, our functional proteomics study confirmed that MBP was hypercitrullinated in women with dementia, but we also observed an unexpected impairment of dMBP degradation, which was associated with reduced cathepsin D expression and increased MBP deamidation at Gln residues (particularly in the degenerative epitope QDENPVV) [15, 41, 42]. Deamidation of Gln residues favors the proteolysis of dysfunctional proteins via the ubiquitin proteasome system [52], but Gln deamidation of brain proteins 


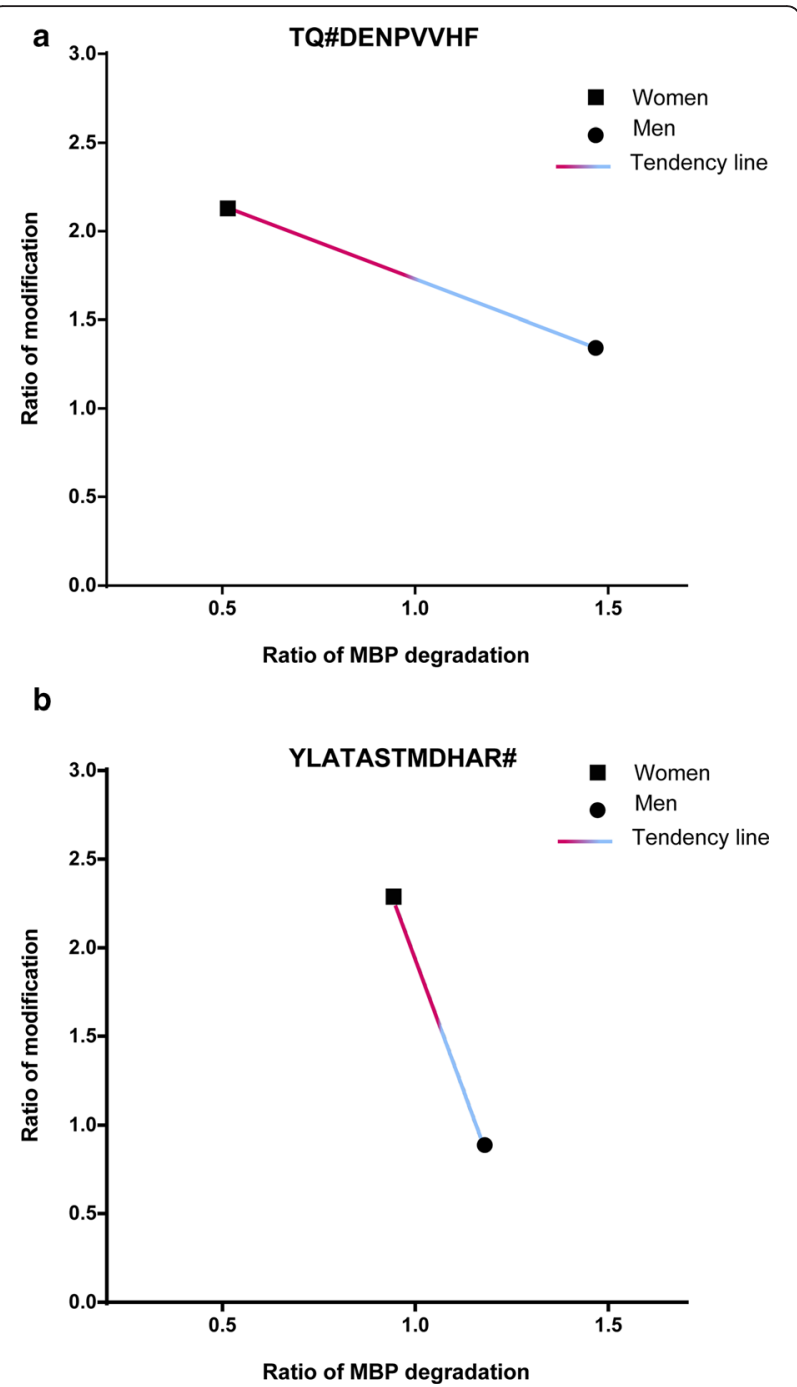

Fig. 3 Degradation of MBP in the temporal lobe of $A D+C V D$ subjects. Degradation ratio of MBP was calculated based on the peptide intensity areas in each group showing exact match with previous reported MBP degradation byproducts by the effect of cathepsin D (see detailed explanation of that method in the material and methods section). All ratios were normalized to age-matched controls (ratio $1=$ normal degradation). a Degradation ratio of the MBP byproduct TQ\#DENPWHF in women and men with dementia. As shown, higher ratio of GIn deamidation (>2.0) in the MBP byproduct TQ\#DENPWHF was associated with lower degradation ratio $(<0.5)$ of the protein in $A D+C V D$ women. $\mathbf{b}$ Degradation ratio of the MBP byproduct YLATASTMDHAR\# in women and men with dementia. MBP degradation ratio of this byproduct in $A D+C V D$ women $(\approx 1)$ was not affected by the increased level of citrullination (ratio $\approx 2.5$ )

including MBP is also strongly associated with proteinopathy $[51,53,54]$ which may resist the degradation of $\mathrm{dMBP}$ by the ubiquitin proteasome system. This impaired clearance of dMBP leads to accumulation of dysfunctional protein in the female brain. Our data now indicate that gender influences on the dementia- associated deamidation of MBP may alter protein degradation in the temporal lobe of $\mathrm{AD}+\mathrm{CVD}$ patients.

We also observed marked up-regulation of several different myelin proteins in the temporal lobe of $\mathrm{AD}+$ CVD subjects, suggestive of an ongoing yet dysfunctional remyelination process [55]. Our data are therefore consistent with a previous report that WM pathology is associated with accumulation of HPLN2, which inhibits axonal remyelination in the brain [55]. Abnormal remyelination may also account for the counterintuitive increase in several myelin proteins including CNP and PLP in the temporal lobe of AD + CVD subjects. Impaired remyelination has previously been characterized to be associated with WM lesions [56], and may also be a feature of patients with AD + CVD, in whom the putative remyelination defect was closely associated with Gln deamidation of MBP.

In a recent study of mice that lack the enzyme Lisoaspartyl methyltransferase (PIMT) which repairs damaged proteins, female animals were reported to exhibit greater accumulation of IsoAsp-type DPMs in the brain [31] . PIMT knock-out mice have also been shown to exhibit increased deamidation and imbalance of the glutamate-glutamine cycle in the brain [57]. These data are consistent with the current report, which suggests that gender-associated increases on deamidation of specific brain proteins may contribute to the increased severity of $A D+C V D$ observed in women. While gender influences on enzymatic citrullination of Arg residues were less marked than effects on Gln deamidation by NADPH1, both processes can liberate ammonia byproducts thought to contribute to WM damage in human dementia [48, 58]. Accordingly, we also detected increased NADPH1 levels together with down-regulation of GS in the temporal lobe of women with AD + CVD. GS are astrocytic enzymes able to efficiently capture free ammonia during the Gln synthesis in the brain $[59,60]$. Down-regulation of GS in the temporal lobe of women with dementia may indicate abnormal production of Gln in the brain, in-turn leading to increased expression of NADPH1 enzymes that enhance production of glutamate from Gln residues. Further research will now be required to assess this possibility.

Whether mitochondria dysfunction precedes changes in the WM proteome or vice versa remains unclear. Other colleagues have reported that an increase in ammonia byproducts during neurodegeneration can exacerbate glutamate toxicity and impair mitochondria function [61]. Here we observed that AD + CVD patients displayed down-regulation of mitochondrial kinase-Utype protein, which is known to be dysregulated in ischemia-induced mitochondrial impairment [62]. We further observed that cytochromes and ATP subunits were significantly altered only in women with $\mathrm{AD}+$ 


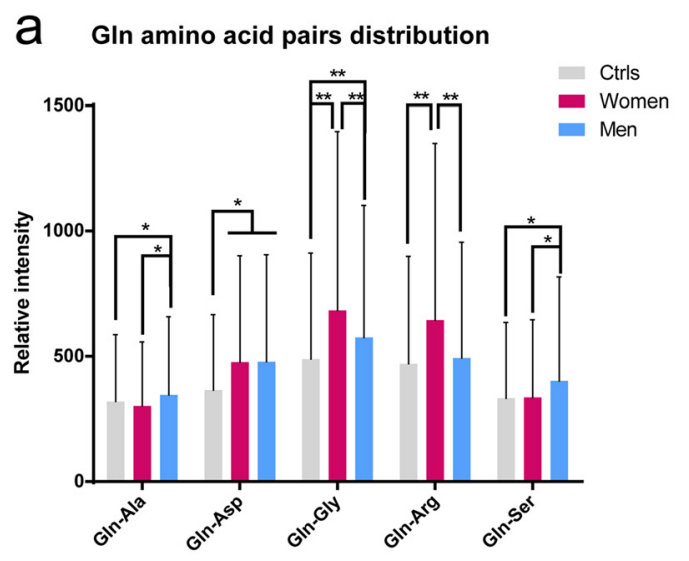

C Arg amino acid pairs distribution
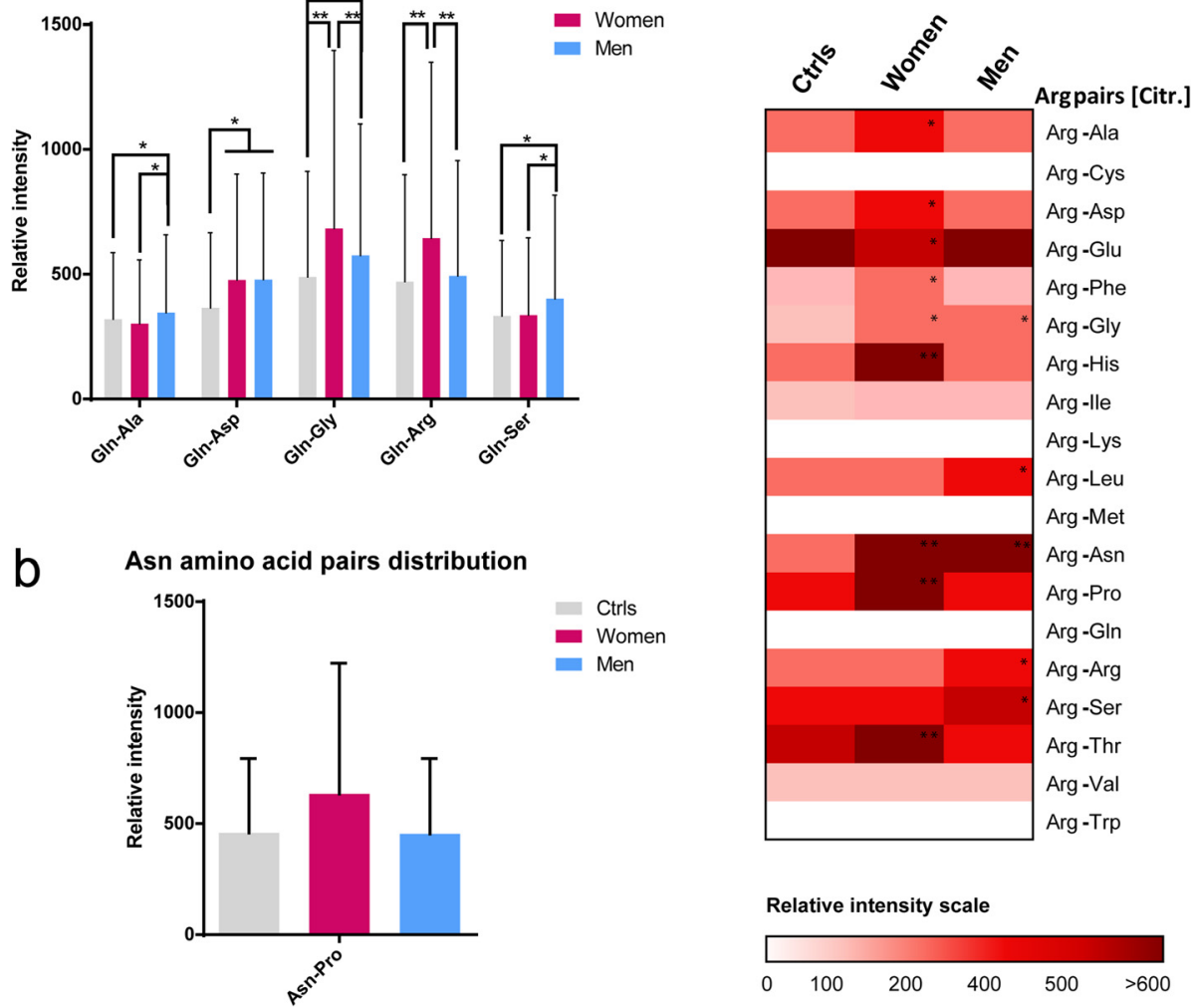

Fig. 4 Characterization of modified amino acid pairs in whole temporal lobe proteome of AD +CVD subjects and controls. a Relative intensity areas of deamidated GIn amino acid pairs in the temporal lobe proteome of age-matched controls, women with dementia, and men with dementia. $\mathbf{b}$ Relative intensity areas of deamidated Asn amino acid pairs in the temporal lobe proteome of age-matched controls, women with dementia, and men with dementia. c Heat map displaying relative intensity areas of Arg citrullination amino acid pairs in whole temporal lobe proteome of age-matched controls, women with dementia, and men with dementia. In the heat map ratio scale red values indicate upregulation of the referred amino acid pair and white values indicate no identification. The following amino acid pairs were not susceptible to Arg citrullination in the temporal lobe of human subjects; Arg-Cys, Arg-Lys, Arg-Met, Arg-Gln and Arg-Trp. Significance level between AD + CVD and controls (* $p<0.05$; ${ }^{* *} p<0.001$ )

CVD, consistent with increased severity of mitochondria dysfunction in this group. According to our findings, perturbation of the mitochondrial proteome appears to be proportional to the severity of WM pathology in human AD + CVD. This result suggests that mitochondria dysfunction in $\mathrm{AD}$-related disorders may be a product of early alterations in the WM proteome by vascular dysfunction, hence as recently suggested the vascular component of disease is likely to exert a major influence on the clinical course of human dementias.

\section{Conclusions}

While several epidemiological and clinical studies have showed that women exhibit higher risk of dementia than men, the molecular neuropathology of this gender difference remains elusive. In the current study, we used unbiased quantitative proteomics to assess the molecular basis of gender influences on risk of $A D+C V D$. For the first time, we report sex-specific molecular differences in white matter pathology and mitochondrial proteomes in the temporal lobe of $\mathrm{AD}+\mathrm{CVD}$ patients. In particular, we observed that hyper-citrullination and hyperdeamidation of MBP were prevalent in female dementia patients. Specifically, deamidation of the glutamine residue 82 in the MBP degenerative epitope was associated with impaired degradation and accumulation of degenerated protein in the temporal lobe of women with dementia. This study uncovers the gender influences on the neuropathology of $\mathrm{AD}+\mathrm{CVD}$, and may pave the way for future clinical interventions that can reduce dementia risk in both male and female patients.

\section{Methods}

Brain tissues

Autopsied brain specimens were carefully evaluated for the presence of senile plaques and CVD at the Newcastle 


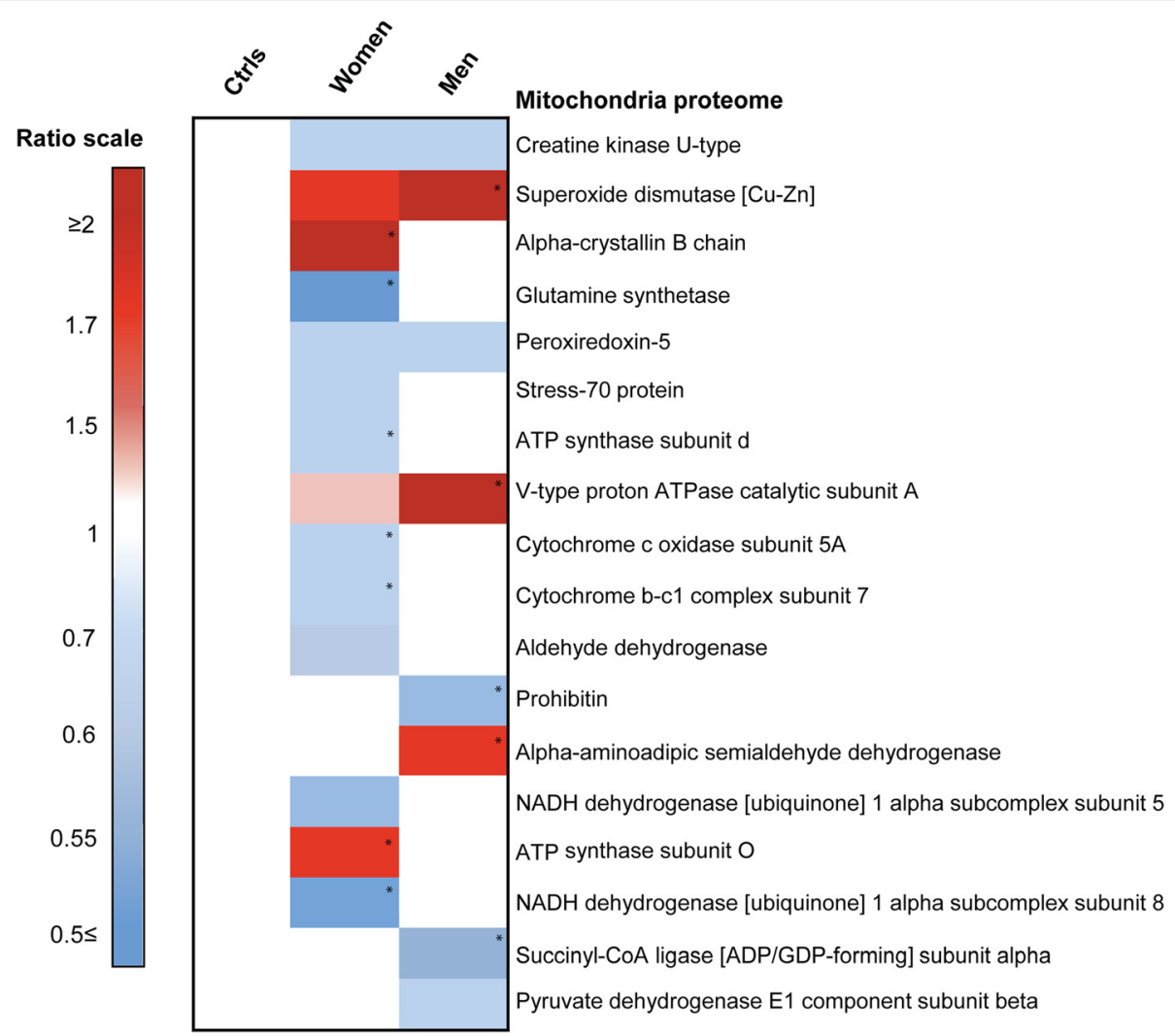

Fig. 5 Heatmap showing ratios of protein enrichment/depletion in the mitochondrial proteome of male and female AD +CVD subjects compared to age-matched controls. Log ratios in AD +CVD subjcets were normalized to controls (controls ratio $=1$ ). Red values represent protein enrichment, blue values represent protein depletion and white values indicate no change in the ratio scale. Protein names were listed on the right side of each heat map line. All proteins reported here are significantly modified versus controls $(p<0.05)$. Significance level between AD + CVD groups (* $p<0.05$ and gender difference $\geq 0.2$ ). Tabular data of values shown in this heat map can be found in Additional file 2: Table S2

Brain Tissue Resource (NBTR, UK). The temporal cortex region BA21 was used in all experiments (both control and dementia samples). All dementia brain samples met histological criteria for $\mathrm{AD}+\mathrm{CVD}$, whereas control subjects lacked features of either dementia or $A D+C V D$. Brain samples in each experimental group were closely matched for key variables including post-mortem delay, cognitive assessment data, age at death, and histological evaluation (Table 1) [63]. Finally, BA21 tissues for western blot validation of the PLP level were generously provided by the Harvard brain tissue resource center (HBTRC). Informed consent was obtained from all participants or their legal representatives. All experimental procedures were approved by the ethical boards at Nanyang Technological University (NTU, Singapore) and NBTR, and were performed in accordance with NTU guidelines.

\section{Reagents}

All reagents were purchased from Sigma-Aldrich (St. Louis, MO, USA) unless specified otherwise.

\section{Tissue processing and protein extraction}

In order to minimize potential confounding factors and to efficiently limit the excessive cost of iTRAQ experiments, we adopted a pooling strategy for our proteomic analyses [64-66]. Approximately 10 milligrams of brain tissue from each subject was homogenized in $1 \%$ SDS buffer using the tissue homogenizer bullet blender (Next Advance, NY, USA) and then pooled into one of the following three groups: age-matched controls (10 subjects), male dementia subjects ( 5 subjects), and female dementia subjects (5 subjects). Experiments were performed in triplicate, and only those proteins that were confidently identified in all three experiments are reported here (see detailed description of statistical analyses below).

Proteins were acetone-precipitated and quantified by bicinchoninic acid assay. Two-hundred micrograms of protein were resolved by SDS-PAGE and visualized using Coomassie Blue staining. Protein bands were cut and destained in $75 \%$ acetonitrile containing $25 \mathrm{mM}$ triethylammonium bicarbonate (TEAB). Gel cubes were reduced with Tris 2carboxyethyl phosphine hydrochloride $(5 \mathrm{mM})$, alkylated 
with methyl methanethiosulfonate $(10 \mathrm{mM})$, and then dehydrated using acetonitrile. Proteins were digested overnight at $37{ }^{\circ} \mathrm{C}$ in sequencing-grade modified trypsin (Promega, Madison, WI, USA). Peptides were extracted using $50 \%$ acetonitrile in $5 \%$ acetic acid solution under ultrasound sonication, then dried and concentrated using a vacuum concentrator (Eppendorf AG, Hamburg, Germany).

\section{iTRAQ labelling and shotgun mass spectrometry}

Labeling of dried peptides was performed as previously reported [38, 39, 67]. Briefly, 4-plex iTRAQ reagent Multiplex kits (Applied Biosystems, Foster City, CA) were used according to the manufacturer's protocol. Tags were distributed as follows; $114=$ controls; $116=$ women; $117=$ men. The iTRAQ-labeled peptides were desalted using Sep-Pak C18 cartridges (Waters, UK) and fractionated by high-performance liquid chromatography (HPLC) (Shimadzu, Kyoto, Japan) on a PolyWAX LP column $(4.6 \times 200 \mathrm{~mm}, 5 \mu \mathrm{m}, 300 \AA$ ) (PolyLC, Columbia, MD, USA). Buffer A (10 mM ammonium acetate, $85 \%$ acetonitrile, $0.1 \%$ acetic acid) and buffer B (30\% acetonitrile, $0.1 \%$ formic acid) were used to establish a 60 min HPLCgradient at $1 \mathrm{ml} / \mathrm{min}$ flow rate. Chromatograms were recorded at $280 \mathrm{~nm}$. A total of 60 fractions were collected and subsequently combined into 26 fractions according to peak intensities.

LC-MS/MS analysis of the brain peptides was performed using a QSTAR Elite mass spectrometer (Applied Biosystems/MDS Sciex, Foster City, CA, USA) coupled with online nanoflow multidimensional liquid chromatography system (MDLC). A custom-made nanobore C18 column with a picofrit nanospray tip $(75 \mu \mathrm{m} \mathrm{ID} \times 15 \mathrm{~cm}$, $5 \mu \mathrm{m}$ particles) was used to separate the iTRAQ-labeled peptides. The QSTAR Elite was set to positive ion mode using Analyst QS 2.0 software for data acquisition (Applied Biosystems, Foster City, CA, USA). The precursors with a mass range of $300-1600 \mathrm{~m} / \mathrm{z}$ and calculated charge from +2 to +5 were selected for fragmentation. Peptides above a 5-count threshold were selected for MS/MS and each selected target ion was dynamically excluded for $20 \mathrm{~s}$ with a mass tolerance of $0.1 \mathrm{Da}$. Smart information-dependent acquisition was activated with automatic collision energy and automatic MS/MS accumulation. The fragment intensity multiplier was set to 20 , and the maximum accumulation time was $2 \mathrm{~s}$.

\section{LC-MS/MS data search}

MS/MS data searching was performed using the concatenated target-decoy Uniprot database in ProteinPilot software 3.0 (revision number 114732; Applied Biosystems, Foster City, CA, USA) with Paragon (3.0.0.0, 113442) and Pro Group algorithms implemented. Digestion enzyme was set as semi-trypsin. User-defined parameters and false discovery rate (FDR) for assignation of peptides and proteins in the software were set as previously specified [38]. Briefly FDR $<1 \%$ (FDR = $2.0 \times$ [decoy hits/total hits] $\times 100 \%$ ) and unused Protein Score value $\geq 2$ were used as qualification criteria (corresponding to a confidence limit of $99 \%$ ). These criteria enabled the identification of over 2400 total proteins.

\section{Regulation of protein levels and statistical inference}

The Pro Group algorithm in Protein Pilot was used to automatically calculate the iTRAQ reporter ratio for each protein based on error factor and $p$-value; Error factor $=$ $1095 \%$ confidence error where $95 \%$ confidence error $=S_{\mathrm{MW}} \times$ (Student's $t$ factor for $n-1^{\circ}$ of freedom). $S_{\mathrm{MW}}$ refers to weighted standard deviation of the weighted average of $\log$ ratios, and $n$ refers to number of peptides contributing to protein relative quantification. P-values were determined by calculating Student's $t$ factor where $t=$ (weighted average of $\log$ ratios - log bias) divided by weighted standard deviation; which allowed determination of $p$-value with $n-1^{\circ}$ of freedom. The statistical criteria used by Paragon and Pro Group algorithms in Protein Pilot have been described in detail elsewhere [68, 69]. Regulation cut-offs to identify protein differential expression between dementia groups and controls were established based on the calculated percentage coefficient of variation (\% CV) of the protein ratios. A total $95 \%$ of the proteins identified in our study displayed a ratio $\% \mathrm{CV}<50 \%$ (Additional file 3: Figure S1A). Accordingly, we set the ratio threshold at $>1.5$ for protein up-regulation and at $<0.67(1 / 1.5)$ for protein down-regulation. No significant differences were observed for \% CV of ratios between the male and female dementia groups, indicating successful control of outliers in each respective pool. Furthermore, no significant differences were observed in postmortem delay mean confidence intervals between experimental groups (Additional file 3: Figure S1B). In order to increase confidence in detecting changes in protein expression level, we then combined these data with a G-test calculation [70] for each protein using only those contributor peptides identified with $\geq 99 \%$ of confidence. G-values were calculated as follows:

$$
\begin{aligned}
G & =2 \times\left(\operatorname{Ctrl}_{A} \times \ln \left[C t r l_{A} \div\left(\left(\operatorname{Ctrl}_{A}+\operatorname{Dem}_{A}\right) \div 2\right)\right]\right. \\
& \left.+\operatorname{Dem}_{A} \times \ln \left[\operatorname{Dem}_{A} \div\left(\left(\operatorname{Ctrl}_{A}+\operatorname{Dem}_{A}\right) \div 2\right)\right]\right)
\end{aligned}
$$

In this equation, $\mathrm{Ctrl}_{\mathrm{A}}$ refers to $\mathrm{iTRAQ}$ reporter area in the control group, Dem ${ }_{\mathrm{A}}$ refers to iTRAQ reporter area of the respective dementia group, and 'In' refers to the natural logarithm. G-values fit well to the $x^{2}$ distribution with one degree of freedom [66], and accordingly, we were able to calculate the corresponding $p$-value for each $\mathrm{G}$-value obtained. Finally, the calculated $p$-values were corrected for multiple comparisons using the Benjamini-Hochberg 
FDR correction at $0.05 \alpha$ [71] to obtain a corrected $p$-value of 0.014. Following this approach, we considered only those proteins confidently identified in all three experiments (i.e. those containing at least one unique peptide identified with $>99 \%$ confidence in each group, and displaying a G-test $p$-value lower than 0.014). A total of 321 proteins satisfied these stringent criteria (Additional file 4) and (Additional file 3: Figure S1C). We then assessed the influence of gender on expression of the 321 proteins identified by analyzing the $\% \mathrm{CV}$ of the iTRAQ ratios in both the male and female dementia groups. The cut-off for protein differential expression between men and women with dementia was set at $\geq 0.2$ (based on $\% \mathrm{CV}$ $<20 \%$ ([116:114] - [117:114]) (Additional file 3: Figure S1D). Combining all the statistical approaches described above, we observed that a total of 59 proteins were significantly modulated in the dementia groups compared with controls (Additional file 5), including 38 proteins that were differentially expressed between male and female dementia patients (Additional file 6).

\section{Quantification of peptide modifications and statistical inference}

To confidently quantify the level of modified peptides in our profiled $\mathrm{AD}+\mathrm{CVD}$ brain tissues we assessed influence of age and disease on the increase of deamidation and citrullination in temporal lobe proteins performing spectral counting in peaks [72]. This analysis confirmed the exacerbate increase of DPTMs in temporal lobe proteins as a disease-associated process (Additional file 3: Figure S1E and S1F). Analysis of modified peptides (deamidation and citrullination) was performed using unique peptide iTRAQ reporter peak areas. Only those peptides identified with $\geq$ $99 \%$ confidence were included in this analysis. Mean peptide reporter peak areas in each of the three groups (age-matched controls, men with dementia, women with dementia) were compared by One-Way ANOVA, and $p$ values were corrected for multiple comparisons using Bonferroni. Data were reported as mean and SD unless stated otherwise.

\section{Molecular bioinformatics and MBP functional proteomics}

MitoMiner was used for analysis of the mitochondria proteome [73]. I-Tasser suite [74] was used for MBP modelling, and Pymol was used to render the 3D structure of the protein [75]. Using previously reported LC-MS/MS data on the byproducts of bovine MBP degradation [43], we performed functional proteomics to investigate the degradation profile of MBP in the temporal lobe of $\mathrm{AD}+$ CVD post-mortem brain tissues. Initially, pairwise alignment between bovine and human MBP sequences was performed using EMBOSS Needle [76] (Additional file 7: Figure S2). Semi-trypsin was enabled during database search. Two criteria were applied to detect MBP peptides as degradation byproducts: (1) an "exact match" between the identified peptide and the peptide obtained by pairwise alignment, and (2) the presence of modified Lys/Arg at the terminal sites of the peptides (thereby rejecting the tryptic-digested peptides generated during sample processing). Using these criteria, the MBP degradation byproducts TQDENPVVHF and YLATASTMDHAR\# (\# referring to Arg citrullination) were identified with $\geq 99 \%$ confidence. MBP percentage degradation was calculated using the following equation:

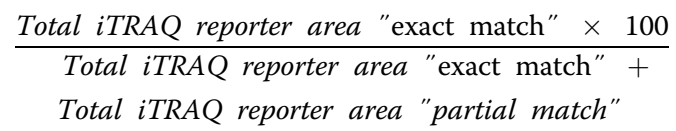

In this equation, "exact match" refers to the identified MBP degradation byproducts described above. "Partial match" refers to longer tryptic peptides that included the exact match sequence of the degradation byproducts. Total iTRAQ reporter area refers to the sum of all identified iTRAQ reporter peak areas for the peptide. The calculation was performed in each group including agematched controls, women with dementia, and men with dementia. Finally, the degradation ratio was obtained by dividing the MBP percentage degradation values for the women and men dementia groups by that calculated for age-matched controls.

\section{Western blot}

Tissues from two AD + CVD women (68y and 79y respectively), two $\mathrm{AD}+\mathrm{CVD}$ men (74y and 63y respectively), one male control $(77 y)$ and one female control $(77 y)$ were homogenized as described above in $1 \%$ SDS buffer. Western blot was performed as previously reported [77]. Briefly, proteins were reduced by 2 -mercaptoethanol $(5 \%)$ in $95{ }^{\circ} \mathrm{C}$ during five minutes and subsequently mixed with BioRad $2 \times$ Laemmli sample buffer (CA, USA). Protein amount was quantified by Bradford assay and equal amount of protein was loaded in a $15 \%$ SDS-PAGE gel. Resolved proteins were then blotted onto a nitrocellulose membrane and detected using the polyclonal goat anti-PLP (SC-23570) primary antibody (1:1000 dilution) and the rabbit anti-goat (SC-2768) secondary antibody (1:3000 dilution). Ponceau staining was used as loading control [78]. Densitometry of Western blot signal was mesured using ImageJ (Rasband W.S., ImageJ. U.S. National Institutes of Health, MD., U.S.A. http://imagej.nih.gov/ij/ 1997-2016) and Student's ttest analysis of data was performed.

\section{Data deposition}

Proteomics data have been made publicly available through ProteomeXchange consortium [79] via the partner repository PRIDE under the following identifier PXD003027. 


\section{Additional files}

Additional file 1: Table S1. Tabular data of differential regulated white matter proteome in BA21 of AD + CVD subjects compared to agematched controls. 1. $p$-value of women/control groups. 2. p-value of men/control groups. (DOC 33 kb)

Additional file 2: Table S2. Tabular data of differential regulated mitochondrial proteome in BA21 of AD + CVD subjects compared to agematched controls. 1. $p$-value of women/control groups. 2. p-value of men/control groups. (DOCX $16 \mathrm{~kb}$ )

Additional file 3: Figure S1. A. Percentage coefficient of variation of calculated iTRAQ ratios. Less than $5 \%$ of protein ratios in dementia groups show a \%CV higher than $50 \%$ (>1.5 ratio). B. Plot of the postmortem delay confidence intervals showing no significant differences between the experimental groups which indicates no effect of this variable on the identified proteome changes. C. Number of $99 \%$ of confidence identified peptides included in our study based on the obtained G-test $p$-values after FDR correction $(p<0.014)$. D. Percentage coefficient of variation of G-test significant proteins in AD with CVD women and men groups. $95 \%$ of the proteins showed less than $20 \%$ of differential variation between groups. E. Analysis of age influence on the occurrence of DPTMs (Asn/Gln deamidation and Arg citrullination) in the temporal lobe of AD + CVD versus Control. Younger patient displayed significantly higher levels of DPTMs in whole BA21 proteome compared to a significantly older control. F. Spectral count of MBP DPTMs (Asn/Gln deamidation and Arg citrullination) in the temporal lobe of $A D+C V D$ versus Control. Younger patient displayed significantly higher levels of DPTMs on the MBP profile compared to a significantly older control. (PDF $255 \mathrm{~kb}$ )

Additional file 4: Dataset containing the total number of temporal lobe proteins that passed the FDR correction applied to the calculated G-test p-values. (XLS $140 \mathrm{~kb}$ )

Additional file 5: Dataset containing the total number of proteins significantly modulated in the temporal lobe of AD+CVD patients compared to controls. (XLS $44 \mathrm{~kb}$ )

Additional file 6: Dataset containing the total number of proteins significantly modulated by the effect of gender in the temporal lobe of AD+CVD patients. (XLS $37 \mathrm{~kb}$ )

Additional file 7: Figure S2. Structural alignment of human and bovine MBP sequences. EMBOSS_001 corresponds to human MBP and MBP_Bovine corresponds to bovine MBP. (PDF $231 \mathrm{~kb}$ )

\section{Competing interests}

The authors declare that they have no competing interests.

\section{Authors' contributions}

$X G P, B S T L, S S A, J Q, A S$ and JEP performed proteomics experiments and analyzed data. XGP and BLST performed bioinformatics and functional proteomics studies. MKPL, CPC and RNK performed histologic examinations and provided clinical samples. SKS conceived the idea and supervised the experiments. XGP and SKS wrote the paper. All authors have read and approved the manuscript.

\section{Acknowledgements}

This work was funded by the Singapore Ministry of Health (NMRC/CBRG/ 0004/2012), Singapore Ministry of Education (Tier1: RGT15/13) and NTU-NHG Ageing Research Grant (ARG/14017). Tissues for this study were provided by Newcastle Brain Tissue Resource as part of the UK Brains for Dementia Research initiative and by Harvard Brain Tissue Resource Center (HBTRC) which is supported in part by a PHS contract and by HHSN-271-201300030C. We thank Louis Fernandes from HBTRC for his kind help and consideration. We also thank Dr. Bamaprasad Dutta for his help with the staining experiments. The authors feel greatly indebted to all the subjects and their families that have participated in this study.

\section{Author details}

${ }^{1}$ Division of Chemical Biology \& BioTechnology, School of Biological Sciences, Nanyang Technological University, 60 Nanyang Drive, Singapore
637551, Singapore. ${ }^{2}$ Department of Pharmacology, Yong Loo Lin School of Medicine, National University of Singapore, Singapore, Singapore. ${ }^{3}$ Memory, Aging and Cognition Centre, National University Health System, Singapore, Singapore. ${ }^{4}$ Institute for Ageing and Health, NIHR Biomedical Research Building, Newcastle University, Campus for Ageing and Vitality, Newcastle upon Tyne NE4 5PL, UK.

Received: 30 October 2015 Accepted: 22 February 2016

Published online: 17 March 2016

\section{References}

1. de Leeuw FE, de Groot JC, Achten E, Oudkerk M, Ramos LM, Heijboer R, et al. Prevalence of cerebral white matter lesions in elderly people: a population based magnetic resonance imaging study. The Rotterdam scan study. J Neurol Neurosurg Psychiatry. 2001;70(1):9-14.

2. van den Heuvel DM, Admiraal-Behloul F, ten Dam VH, Olofsen H, Bollen EL, Murray HM, et al. Different progression rates for deep white matter hyperintensities in elderly men and women. Neurology. 2004;63(9):1699-701.

3. Kalaria R. Similarities between Alzheimer's disease and vascular dementia. J Neurol Sci. 2002;203-204:29-34.

4. Gold G, Giannakopoulos P, Bouras C. Re-evaluating the role of vascular changes in the differential diagnosis of Alzheimer's disease and vascular dementia. Eur Neurol. 1998;40(3):121-9.

5. ladecola C. The pathobiology of vascular dementia. Neuron. 2013;80:844-66.

6. Prins ND, Scheltens P. White matter hyperintensities, cognitive impairment and dementia: an update. Nat Rev Neurol. 2015;11(3):157-65. doi:10.1038/ nrneurol.2015.10.

7. Attems J, Jellinger KA. The overlap between vascular disease and Alzheimer's disease-lessons from pathology. BMC Med. 2014;12:206.

8. Pantoni L, Garcia JH. Pathogenesis of leukoaraiosis: a review. Stroke. 1997; 28(3):652-9.

9. Kalaria RN. The role of cerebral ischemia in Alzheimer's disease. Neurobiol Aging. 2000;21:321-30

10. Kalaria RN, Ihara M. Dementia: vascular and neurodegenerative pathways[mdash]will they meet? Nat Rev Neurol. 2013;9(9):487-8.

11. Fernando MS, Simpson JE, Matthews F, Brayne C, Lewis CE, Barber R, et al. White matter lesions in an unselected cohort of the elderly: molecular pathology suggests origin from chronic hypoperfusion injury. Stroke. 2006;37(6):1391-8.

12. Haight TJ, Landau SM, Carmichael O, et al. Dlssociable effects of Alzheimer disease and white matter hyperintensities on brain metabolism. JAMA Neurol. 2013;70(8):1039-45.

13. Vermeer SE, Prins ND, den Heijer T, Hofman A, Koudstaal PJ, Breteler MM. Silent brain infarcts and the risk of dementia and cognitive decline. N Eng J Med. 2003;348(13):1215-22.

14. Brickman AM, Zahodne LB, Guzman VA, Narkhede A, Meier IB, Griffith EY, et al. Reconsidering harbingers of dementia: progression of parietal lobe white matter hyperintensities predicts Alzheimer's disease incidence. Neurobiol Aging. 2015:36(1):27-32.

15. Ihara M, Polvikoski TM, Hall R, Slade JY, Perry RH, Oakley AE, et al. Quantification of myelin loss in frontal lobe white matter in vascular dementia, Alzheimer's disease, and dementia with Lewy bodies. Acta Neuropathol. 2010;119(5):579-89.

16. Vemuri P, Lesnick TG, Przybelski SA, Knopman DS, Preboske GM, Kantarci K, et al. Vascular and amyloid pathologies are independent predictors of cognitive decline in normal elderly. Brain. 2015;138:761-71.

17. Inzitari D, Pracucci G, Poggesi A, Carlucci G, Barkhof F, Chabriat H, et al. Changes in white matter as determinant of global functional decline in older independent outpatients: three year follow-up of LADIS study cohort. BMJ. 2009:339:b2477.

18. Boggs JM. Myelin basic protein: a multifunctional protein. Cell Mol Life Sci. 2006;63(17):1945-61.

19. Gravel M, Peterson J, Yong WW, Kottis V, Trapp B, Braun PE. Overexpression of 2',3'-cyclic nucleotide 3'-phosphodiesterase in transgenic mice alters oligodendrocyte development and produces aberrant myelination. Mol Cell Neurosci. 1996;7(6):453-66.

20. Readhead C, Schneider A, Griffiths I, Nave KA. Premature arrest of myelin formation in transgenic mice with increased proteolipid protein gene dosage. Neuron. 1994;12(3):583-95.

21. Lutz D, Loers G, Kleene R, Oezen I, Kataria H, Katagihallimath $N$, et al. Myelin basic protein cleaves cell adhesion molecule $\mathrm{L} 1$ and promotes neuritogenesis and cell survival. J Biochem. 2014;289(19):13503-18. 
22. Zhang C, Walker AK, Zand R, Moscarello MA, Yan JM, Andrews PC. Myelin basic protein undergoes a broader range of modifications in mammals than in lower vertebrates. J Proteome Res. 2012;11(10):4791-802.

23. Wood DD, Moscarello MA. The isolation, characterization, and lipidaggregating properties of a citrulline containing myelin basic protein. J Biol Chem. 1989:264(9):5121-7.

24. Bartzokis G. Age-related myelin breakdown: a developmental model of cognitive decline and Alzheimer's disease. Neurobiol Aging. 2004;25(1):5-18

25. Kalaria RN. Cerebrovascular disease and mechanisms of cognitive impairment: evidence from clinicopathological studies in humans. Stroke. 2012;43(9):2526-34.

26. Chen H, Chan DC. Critical dependence of neurons on mitochondrial dynamics. Curr Opin Cell Biol. 2006;18(4):453-9.

27. Funfschilling U, Supplie LM, Mahad D, Boretius S, Saab AS, Edgar J, et al. Glycolytic oligodendrocytes maintain myelin and long-term axonal integrity. Nature. 2012;485(7399):517-21.

28. Morato L, Bertini E, Verrigni D, Ardissone A, Ruiz M, Ferrer l, et al. Mitochondrial dysfunction in central nervous system white matter disorders. Glia. 2014;62(11):1878-94.

29. Gudmann NS, Hansen NU, Jensen AC, Karsdal MA, Siebuhr AS. Biological relevance of citrullinations: diagnostic, prognostic and therapeutic options. Autoimmunity. 2015:48(2):73-9.

30. Gallart-Palau X, Serra A, Sze SK. Uncovering neurodegenerative protein modifications via proteomic profiling. Int Rev Neurobiol. 2015:121:87-116.

31. Qin Z, Kaufman RS, Khoury RN, Khoury MK, Aswad DW. Isoaspartate accumulation in mouse brain is associated with altered patterns of protein phosphorylation and acetylation, some of which are highly sex-dependent. PLoS One. 2013;8, e80758.

32. Harbo HF, Gold R, Tintore M. Sex and gender issues in multiple sclerosis. Ther Adv Neurol Disor. 2013;6(4):237-48.

33. Choudhary J, Grant SG. Proteomics in postgenomic neuroscience: the end of the beginning. Nat Neurosci. 2004;7(5):440-5.

34. Cao J, Wang J, Dwyer JB, Gautier NM, Wang S, Leslie FM, et al. Gestational nicotine exposure modifies myelin gene expression in the brains of adolescent rats with sex differences. Transl Psychiatry. 2013;3, e247.

35. Barker R, Wellington D, Esiri MM, Love S. Assessing white matter ischemic damage in dementia patients by measurement of myelin proteins. J Cereb Blood Flow Metab. 2013;33(7):1050-7.

36. Aboul-Enein F, Rauschka H, Kornek B, Stadelmann C, Stefferl A, Bruck W, et al. Preferential loss of myelin-associated glycoprotein reflects hypoxia-like white matter damage in stroke and inflammatory brain diseases. J Neuropathol Exp Neurol. 2003;62(1):25-33.

37. Ishigami A, Maruyama N. Importance of research on peptidylarginine deiminase and citrullinated proteins in age-related disease. Geriatr Gerontol Int. 2010;10 Suppl 1:S53-8.

38. Gallart-Palau X, Serra A, Qian J, Chen CP, Kalaria RN, Sze SK. Temporal lobe proteins implicated in synaptic failure exhibit differential expression and deamidation in vascular dementia. Neurochem Int. 2015;80:87-98.

39. Adav SS, Qian J, Ang YL, Kalaria RN, Lai MK, Chen CP, et al. iTRAQ quantitative clinical proteomics revealed role of $\mathrm{Na}(+) \mathrm{K}(+)$-ATPase and its correlation with deamidation in vascular dementia. J Proteome Res. 2014; 13(11):4635-46.

40. Hamada K, Terauchi A, Nakamura K, Higo T, Nukina N, Matsumoto N, et al. Aberrant calcium signaling by transglutaminase-mediated posttranslational modification of inositol 1,4,5-trisphosphate receptors. Proc Natl Acad Sci U S A. 2014;111(38):E3966-75.

41. Tomimoto H, Akiguchi I, Matsuo A, Terai K, Wakita H, Kimura J, et al. Encephalitogenic peptide (EP) in human cerebrovascular white matter lesions. Neuroreport. 1997;8(17):3727-30.

42. Matsuo A, Lee GC, Terai K, Takami K, Hickey WF, McGeer EG, et al. Unmasking of an unusual myelin basic protein epitope during the process of myelin degeneration in humans: a potential mechanism for the generation of autoantigens. Am J Pathol. 1997;150(4):1253-66.

43. Bacheva AV, Belogurov AA, Kuzina ES, Serebryakova MV, Ponomarenko NA Knorre VD, et al. Functional degradation of myelin basic protein. The proteomic approach. Russ J Bioorg Chem. 2011;37(1):39-47.

44. Takata T, Oxford JT, Brandon TR, Lampi KJ. Deamidation alters the structure and decreases the stability of human lens betaA3-crystallin. Biochemistry. 2007:46(30):8861-71

45. Liu B, Wang G, Gao D, Gao F, Zhao B, Qiao M, et al. Alterations of GABA and glutamate-glutamine levels in premenstrual dysphoric disorder: a $3 \mathrm{~T}$ proton magnetic resonance spectroscopy study. Psychiatry Res. 2015;231(1):64-70.
46. Yucel M, Wood SJ, Wellard RM, Harrison BJ, Fornito A, Pujol J, et al. Anterio cingulate glutamate-glutamine levels predict symptom severity in women with obsessive-compulsive disorder. Aust N Z J Psychiatry. 2008;42(6):467-77.

47. Long J, He P, Shen Y, Li R. New evidence of mitochondria dysfunction in the female Alzheimer's disease brain: deficiency of estrogen receptor-beta. J Alzheimers Dis. 2012:30(3):545-58.

48. De Ingeniis J, Kazanov MD, Shatalin K, Gelfand MS, Osterman AL, Sorci L. Glutamine versus ammonia utilization in the NAD synthetase family. PLoS One. 2012;7(6), e39115.

49. Yamamoto Y, Ihara M, Tham C, Low RW, Slade JY, Moss T, et al. Neuropathological correlates of temporal pole white matter hyperintensities in CADASIL. Stroke. 2009;40(6):2004-11.

50. D'Souza CA, Wood DD, She YM, Moscarello MA. Autocatalytic cleavage of myelin basic protein: an alternative to molecular mimicry. Biochemistry. 2005:44(38):12905-13.

51. Wood DD, Ackerley CA, Brand B, Zhang L, Raijmakers R, Mastronardi FG, et al. Myelin localization of peptidylarginine deiminases 2 and 4 : comparison of PAD2 and PAD4 activities. Lab Invest. 2008;88(4):354-64.

52. Dudek EJ, Lampi KJ, Lampi JA, Shang F, King J, Wang Y, et al. Ubiquitin proteasome pathway-mediated degradation of proteins: effects due to sitespecific substrate deamidation. Invest Ophthalmol Vis Sci. 2010;51(8):4164-73.

53. Robinson NE, Robinson AB. Deamidation of human proteins. Proc Natl Acad Sci U S A. 2001;98(22):12409-13.

54. Boggs JM, Yip PM, Rangaraj G, Jo E. Effect of posttranslational modifications to myelin basic protein on its ability to aggregate acidic lipid vesicles. Biochemistry. 1997;36(16):5065-71.

55. Sherman LS, Back SA. A 'GAG' reflex prevents repair of the damaged CNS. Trends Neurosci. 2008;31(1):44-52.

56. Jonsson M, Zetterberg $H$, Rolstad S, Edman A, Gouw AA, Bjerke M, et al. Low cerebrospinal fluid sulfatide predicts progression of white matter lesions - the LADIS study. Dement Geriatr Cogn Disord. 2012;34(1):61-7.

57. Yang $H$, Lowenson JD, Clarke S, Zubarev RA. Brain proteomics supports the role of glutamate metabolism and suggests other metabolic alterations in protein l-isoaspartyl methyltransferase (PIMT)-knockout mice. J Proteome Res. 2013;12(10):4566-76.

58. Lu X, Galkin A, Herzberg O, Dunaway-Mariano D. Arginine deiminase uses an active-site cysteine in nucleophilic catalysis of L-arginine hydrolysis. J Am Chem Soc. 2004;126(17):5374-5.

59. Suarez I, Bodega G, Fernandez B. Glutamine synthetase in brain: effect of ammonia. Neurochem Int. 2002:41(2-3):123-42.

60. Kosenko E, Llansola M, Montoliu C, Monfort P, Rodrigo R, Hernandez-Viadel M, et al. Glutamine synthetase activity and glutamine content in brain: modulation by NMDA receptors and nitric oxide. Neurochem Int. 2003:43(4-5):493-9.

61. Bobermin LD, Wartchow KM, Flores MP, Leite MC, Quincozes-Santos A, Goncalves CA. Ammonia-induced oxidative damage in neurons is prevented by resveratrol and lipoic acid with participation of heme oxygenase 1. Neurotoxicology. 2015;49:28-35.

62. Karpati G, Carpenter S, Melmed C, Eisen AA. Experimental ischemic myopathy. J Neurol Sci. 1974:23(1):129-61.

63. Hynd MR, Lewohl JM, Scott HL, Dodd PR. Biochemical and molecular studies using human autopsy brain tissue. J Neurochem. 2003:85(3):543-62.

64. Allison DB, Cui X, Page GP, Sabripour M. Microarray data analysis: from disarray to consolidation and consensus. Nat Rev Genet. 2006;7(1):55-65.

65. Weinkauf M, Hiddemann W, Dreyling M. Sample pooling in 2-D gel electrophoresis: a new approach to reduce nonspecific expression background. Electrophoresis. 2006;27(22):4555-8.

66. Kendziorski CM, Zhang $Y$, Lan $H$, Attie AD. The efficiency of pooling mRNA in microarray experiments. Biostatistics. 2003;4(3):465-77.

67. Datta A, Qian J, Chong R, Kalaria RN, Francis P, Lai MK, et al. Novel pathophysiological markers are revealed by iTRAQ-based quantitative clinical proteomics approach in vascular dementia. J Proteomics. 2014;99:54-67.

68. Lu H, Yang Y, Allister EM, Wijesekara N, Wheeler MB. The identification of potential factors associated with the development of type 2 diabetes: a quantitative proteomics approach. Mol Cell Proteomics. 2008;7(8):1434-51.

69. Shilov IV, Seymour SL, Patel AA, Loboda A, Tang WH, Keating SP, et al. The Paragon Algorithm, a next generation search engine that uses sequence temperature values and feature probabilities to identify peptides from tandem mass spectra. Mol Cell Proteomics. 2007:6(9):1638-55.

70. Bai B, Hales CM, Chen P-C, Gozal Y, Dammer EB, Fritz JJ, et al. U1 small nuclear ribonucleoprotein complex and RNA splicing alterations in Alzheimer's disease. Proc Natl Acad Sci U S A. 2013;110(41):16562-7. 
71. Ghosh D. Incorporating the empirical null hypothesis into the BenjaminiHochberg procedure. Stat Appl Genet Mol Biol. 2012;11(4):doi: 10.1515/ 1544-6115.1735.

72. Ma B, Zhang K, Hendrie C, Liang C, Li M, Doherty-Kirby A, et al. PEAKS: powerful software for peptide de novo sequencing by tandem mass spectrometry. Rapid Commun Mass Spectrom. 2003;17(20):2337-42.

73. Smith AC, Blackshaw JA, Robinson AJ. MitoMiner: a data warehouse for mitochondrial proteomics data. Nucleic Acids Res. 2012;40:1160-7.

74. Yang J, Yan R, Roy A, Xu D, Poisson J, Zhang Y. The I-TASSER suite: protein structure and function prediction. Nat Methods. 2015;12(1):7-8.

75. Bramucci E, Paiardini A, Bossa F, Pascarella S. PyMod: sequence similarity searches, multiple sequence-structure alignments, and homology modeling within PyMOL. BMC Bioinformatics. 2012;13 Suppl 4:S2

76. Li W, Cowley A, Uludag M, Gur T, McWilliam H, Squizzato S, et al. The EMBLEBI bioinformatics web and programmatic tools framework. Nucleic Acids Res. 2015;43(W1):580-4.

77. Gallart-Palau X, Serra A, Wong AS, Sandin S, Lai MK, Chen CP, et al. Extracellular vesicles are rapidly purified from human plasma by PRotein Organic Solvent PRecipitation (PROSPR). Sci Rep. 2015;5:14664.

78. Romero-Calvo I, Ocón B, Martínez-Moya P, Suárez MD, Zarzuelo A, MartínezAugustin $\mathrm{O}$, et al. Reversible Ponceau staining as a loading control alternative to actin in Western blots. Anal Biochem. 2010:401(2):318-20.

79. Vizcaino JA, Deutsch EW, Wang R, Csordas A, Reisinger F, Rios D, et al. ProteomeXchange provides globally coordinated proteomics data submission and dissemination. Nat Biotechnol. 2014;32(3):223-6.

\section{Submit your next manuscript to BioMed Central and we will help you at every step:}

- We accept pre-submission inquiries

- Our selector tool helps you to find the most relevant journal

- We provide round the clock customer support

- Convenient online submission

- Thorough peer review

- Inclusion in PubMed and all major indexing services

- Maximum visibility for your research

Submit your manuscript at www.biomedcentral.com/submit 